\title{
REFLECTIONS
}

\section{Saved by a syncretic faith? A case from 1995}

\author{
ANURAG BHARGAVA
}

\begin{abstract}
Physicians in countries like India have to take on the care of seriously ill patients that, in a strict sense, maybe beyond their means to handle. They do so often because their patients trust them or the institutions that they may be a part of. The author reflects on his stint as a young physician in a rural medical college in Gujarat in the 1990s. He narrates the experience of dealing with a critically ill young man brought by road from a hospital in Bombay, $500 \mathrm{~km}$ away, to his hometown. The patient survived because the correct diagnosis was reached, and the family assisted in his intensive care with a remarkable composure which owed its origins to a faith crossing the boundaries of religion.
\end{abstract}

Key words: Syncretism; faith; healing; narrative medicine

I was on emergency call early in 1995, at the Pramukhswami Medical College in Karamsad, near Anand in Gujarat. It was my first job as an Assistant Professor in what was then a medical college in a rural area, not yet recognised by the Medical Council of India. It was my first experience of working in rural India after spending six years at the All India Institute of Medical Sciences (AllMS) in New Delhi. The experience of the medical college was quite the opposite of AllMS with its endless waiting lists, and patients desperate to get our ear. At Karamsad on the other hand, I would have to spend a lot of time to convince a woman with severe hypertension and complications and her family, of the need for admission. The major stumbling block in such a case would be the buffalo at home that would create a fuss if milked by any other person than the woman of the family. The patients initially did not care a damn for me, who in their

Author: Anurag Bhargava (anuragb17@gmail.com), Professor, Department of Medicine, Yenepoya Medical College, Deralakatte, Mangalore, Karnataka 575018 INDIA.

To cite: Bhargava A. Saved by a syncretic faith? A case from 1995. Indian J Med Ethics. 2021 Jul-Sep;6(3) NS: 251-253. DOI: 10.20529/JME.2021.017.

Published online first on March 12, 2021.

Manuscript Editor:Vijayaprasad Gopichandran

(c) Indian Journal of Medical Ethics 2021 eyes was a doctor from Delhi who couldn't speak Gujarati. They however accepted me wholeheartedly when, a few months later, I could do so in a passable manner.

The unique feature then of this college, and the major reason for my interest in joining it, were its links with the Tribhovandas Foundation, a large NGO supported by Anand Milk Union Ltd (AMUL), which wanted to replicate in terms of human health what was achieved in terms of animal health by AMUL. I ran outreach clinics for this organisation at two of their centres. The foundation provided, free of charge, daily therapy including rifampicin, and this would draw a lot of patients with suspected TB in the backward district of Balasinor (now famous for India's only Dinosaur fossil park). However, we were dependent on the government for sputum microscopy services and to a hospital for X-rays. I shared the frustration of the patients as they waited, often for weeks, for a microbiological confirmation of diagnosis. In 2004, the publication of a trial in the Lancet finally laid the 8- month regime limiting the use of rifampicin to the initial 2 months to its well-deserved place in the graveyard (1). Ten years earlier, my patients in Balasinor had been telling me that they wanted to continue rifampicin throughout the six months of therapy. I was powerless to change the regime, but since then I have striven to listen more closely to the real experts on any disease -- the patients.

Emergency duties were a different cup of tea in this college then, since there were no post-graduates and junior faculty like me doubled up in the role of residents. I was in the small emergency room seeing another patient when Aslam (not his real name) was wheeled in on the stretcher. He looked desperately ill, unconscious and gasping for breath. I called out for the emergency equipment, and decided to intubate him as a life-saving measure, after taking the concerned but strangely composed relatives into confidence. At that time, the college had a cardiac care unit but no ventilators, so my decision to intubate him committed us to ventilating him by hand using an Ambu-bag. Initially the nurses would do it, and then the relatives would take over. In any case, recoveries from such situations had, till then, been rare

When I later enquired about the details of his illness and looked at the investigation reports, I realised the situation I 
had got into. A few weeks ago he had traveled for some work to Bombay as it was called then. He developed fever for a few days, which was followed by the appearance of jaundice and soon thereafter, alteration of consciousness. He was also noted to have acute kidney failure. Treatment at Bombay had been to no avail, and his condition steadily worsened. The relatives gave up hope after a week and thought of bringing him back home, reconciled to the fact that he would not survive. The journey from Bombay to Anand a distance of nearly $500 \mathrm{~km}$, was by ambulance. However when they reached their village about $20 \mathrm{~km}$ away, Aslam was still breathing. It was then that they came to the college. At that time, there were some private hospitals in Anand which had a better-equipped ICU, but they chose to come to the medical college.

He was unresponsive to pain with severe anaemia, renal failure, jaundice, pneumonia in both lungs, adding up to a critical situation. The hospital at Bombay had diagnosed him as having liver failure following acute hepatitis but I noted that they had not ordered a malaria test, possibly due to lack of suspicion. Kheda district was endemic for plasmodium falciparum malaria and I had a lot of experience with severe falciparum malaria which could be associated with all these complications. His blood films did show severe falciparum malaria, and that was fortunate because it offered a small ray of hope in a desperate situation. He was ventilated using the Ambu bag by his relatives, who took turns in a 3-hour duty shift. I hoped that he would not require dialysis, as there was no dialysis unit in the hospital either. By the third day, things started turning around, with his consciousness, kidney function and pneumonia improving. By the fourth day we could remove the endotracheal tube, much to the relief of his relatives. He stayed in the hospital for 2 more weeks, because he had developed a bad bed sore while in Bombay. When he was discharged the family organised a small celebration, and as they were involved in running a small business selling imported items, gifted a nice watch to the nurses and doctors alike. I acknowledged the gesture but felt it appropriate to hand it over to the authorities, with whom it still lies.

It was in some ways a miraculous recovery, with the long road journey, with the severe involvement of the brain, lungs and kidneys, and the delay in starting appropriate therapy. This particular patient and his recovery was a sort of milestone in my own journey as an itinerant physician and I learnt some valuable lessons. Here was a patient whose diagnosis had been completely missed at a well-equipped hospital in Bombay but was confirmed by my house-officer, who was like his peers an expert at examining thick smears for detecting the malarial parasite. I recalled my struggle to get thick smears for malaria read at AlIMS (the laboratory staff insisted that the less sensitive thin smears were good enough); and also recalled the difficulty we had in procuring quinine for a patient with falciparum malaria in Delhi. Here all those things were perfectly in place. I realised then, and the belief got stronger as time passed, that the skills of the healthcare providers determine the level of care, rather than the brick and mortar and the equipments in a hospital. One can provide prompt high quality care under a thatched roof, and fail to provide it even with state-of -the- art equipment around. Also that providers working at primary and secondary care levels are often more aware of locally prevalent diseases than those working in tertiary care who may not see these patients frequently.

The other lesson for me was the successful management of a patient who required ventilation with the cooperation of the patient's family, with the aid of a simple Ambu bag and oxygen. The family trusted in us and was reluctant to go anywhere else and we persisted with our attempts to do our best. This situation is often the lot of many physicians and surgeons in rural areas where referral to a so-called higher centre is often a myth and doing one's best with a prayer on your lips is often the only real option. At AlIMS, I had never managed a person ventilating only with an Ambu-bag but it was during a stint as a visitor to Christian Fellowship Hospital, Oddanchatram, in 1994, that I saw residents saving lives thus. That gave me some hope and the labours of the family members bore fruit. It was quite a unique situation to see the family intimately involved in the delivery of intensive care, rather than being spectators. There would be other occasions, including in patients with snake bites, that we would be successful in saving lives this way.

The most memorable feature of this incident was the exemplary calm and trust with which the family had conducted itself. I wondered why they chose to come to the college, as they were not really that poor, and what accounted for their composure during his treatment. This was unusual in relatives of a young patient in a lifethreatening situation. The brother finally put my doubts to rest. The family members were followers of Swami Krishnanand, who had lived at the old Shanti Ashram in Bhadran, a nearby village. He was by all accounts a loved, respected figure for them and many others. The Swami had died a few years earlier in 1989, and his body was donated to the medical college as per his wish. The family believed that the spirit of Swami Krishnanand was present in the medical college and this accounted for a large part for their faith in our treatment and their composure.

I never visited the ashram or met any of his other followers. But I did read after this, some of the accounts of his travels across India in books available on the internet. The accounts are mostly about people he met, ordinary people in extraordinary situations, and also of seekers. He himself seems to have had an interesting journey in his life from his birth in Burma, to his fleeing to India during the Second World War, to a peripatetic existence with a final settlement in Gujarat. It is refreshing to find someone in robes stating that the purpose of life is not to attain moksha (salvation) or encounter God, but to become fully human; to state that he was just a seeker with no special powers, to go to great pains 
to explain away the so-called miracles attributed to him; to acknowledge the hospitality of Christian priests in Shillong who helped him when he was in a tight spot.

This incident came back to me in the present, tinged with the sense of loss of a bygone era. Now Karamsad has a large ICU and Oddanchatram too has ventilators. In ICUs across India, patients and their families might spend a good part of their annual income for a day's stay. I wonder whether I would do the same today that I did then, faced with a situation in another setting. I left Gujarat in 1999, though the portents of the events which unfolded later were discernible even then. I wonder if there will ever be more of the likes of
Swami Krishnanand, preaching a simple humanity of peace and brotherhood; and leaving their bodies to a medical college (and in the eyes of their followers their spirits too). I wonder if there are still the likes of Aslam in Gujarat who can access such men representing India's syncretic faith, if and where they do exist.

'Note: These include books like Sermons in the Storms, Light and Darkness, and Pearls and Pebbles all available freely as Google books.

References

1. Jindani A, Nunn AJ, Enarson DA. Two 8-month regimens of chemotherapy for treatment of newly diagnosed pulmonary tuberculosis: international multicentre randomised trial. Lancet. 2004 Oct 2-8:364(9441):1244-51. Doi: 10.1016/S01406736(04)17141-9.

\section{APPEAL FOR DONATIONS TO THE FORUM FOR MEDICAL ETHICS SOCIETY}

The Forum for Medical Ethics Society (FMES), publisher of the Indian Journal of Medical Ethics (IJME), appeals to subscribers, contributors, readers, supporters and well-wishers of IJME and FMES to donate to its corpus and towards the publication of IJME. Contributions from both individuals and institutions are welcome.

FMES has published the journal on a shoestring budget, without a break, since 1993. The journal is known for being open access and spearheading discourse aimed at advancing social justice in health and ethics-centred healthcare and health research reform. It is recognised widely as an authoritative resource of knowledge in bioethics and allied areas of enquiry. FMES and IJME have not only sustained themselves but have grown over these past 25 years. Our ever-growing base of readers, contributors, and reviewers enables the publication of multiple and diverse perspectives on wide-ranging topical areas. We have also striven to upgrade the journal technically to keep up with the advances in publishing to widen our reach. This has been possible only because of your steadfast and sustained support.

We are committed to maintaining our editorial independence which is critical to safeguarding the scientific integrity of what we publish. Therefore, wider support from all those who are committed to social justice in health is essential.

FMES is registered under the Societies Registration Act, 1860 (Reg No: Mumbai-218-1995-G.B.B.D.D) and the Bombay Public Trusts Act, 1950 (Reg No: F-17441 Mumbai, 1995), and donations are eligible for tax exemption under Section 80G of the Income Tax Act, 1961

For more details on how to support us, write to admin@ijme.in or visit our website www.ijme.in/subscribe-support/

SUPPORT OPEN-ACCESS ACADEMIC PUBLICATIONS, DONATE TO THE FMES CORPUS FOR THE PUBLICATION OF IJME! 